\title{
AVALIAÇÃO DA QUALIDADE FÍSICO - QUÍMICOS DO QUEIJO COALHO COMERCIALIZADO NO MUNICÍPIO DE BARREIROS-PE
}

\section{PHYSICOCHEMICAL QUALITY EVALUATION OF MARKETABLE COALHO TYPE CHEESE IN BARREIROS-PE}

\author{
Wilson Luiz Ferreira ${ }^{1}$, João Rufino de Freitas Filho ${ }^{2}$ \\ ${ }^{1}$ Faculdade de Formação de Professores da Mata Sul- FAMASUL - Palmares - Brasil \\ wilsonferreira.lz@bol.com.br \\ ${ }^{2}$ Universidade Federal Rural de Pernambuco - UFRPE/ Unidade Acadêmica de Garanhuns - UAG - \\ Garanhuns -Brasil joaoveronice@yahoocom.br
}

\begin{abstract}
Resumo
O objetivo desta pesquisa foi avaliar a qualidade de físico - químicos do queijo de coalho comercializado no município de Barreiros - PE. As amostras foram coletadas em pequeno supermercado de Barreiros - PE, entre os meses de julho a dezembro. Os valores médios encontrados para os parâmetros físico-químicos foram: umidade-36,37g/100g; cinzas-4,31g $/ 100 \mathrm{~g}$; cloretos-2,00g/100g; acidez- 1,47(g/100g de ácido láctico); extrato seco - 63,56g/100g. Não houve diferença $(p>0,05)$ entre os queijos comercializados em Barreiros/PE para os parâmetros físicoquímicos.
\end{abstract}

Palavras-chave: queijo coalho, qualidade físico-químicos, teor de umidade.

\section{Introdução}

No Brasil, principalmente na Região Nordeste, o queijo de coalho é muito apreciado. A maioria desses queijos tem sua origem ligada à fabricação artesanal, em numerosas unidades de produção caseira e propriedades rurais de pequeno porte, tornando difícil sua quantificação em estatísticas oficiais e, portanto, o controle pelos órgãos de inspeção. O leite utilizado para sua elaboração, normalmente não recebe o beneficiamento térmico, o que impõe sério perigo quanto à contaminação por uma grande variedade de microrganismos. Além disso, essas queijarias utilizam o estômago de animais como coalho, devido à presença da enzima renina contida nesse material, comprometendo ainda mais a qualidade destes produtos [1,2].

No Brasil existem vários tipos de queijos frescos produzidos de forma artesanal e industrial, tanto por pequenos produtores quanto por algumas indústrias. Esses queijos são muito populares e devido ao bom rendimento que proporcionam na fabricação, são comercializados a preços acessíveis a uma maior faixa da população [3]. 
Segundo ALMEIDA FILHO [4] 46\% de toda produção brasileira de leite é comercializada sem qualquer tipo de fiscalização oficial, que observou um consumo anual de aproximadamente 415 mil toneladas de queijo, sendo 200 mil toneladas não inspecionadas compostas basicamente pelo queijo minas frescal [5].

Alimentos como queijo têm se destacado como os derivados lácticos mais consumidos, devido ao seu alto teor de proteínas e outros nutrientes [6].

A qualidade dos produtos lácteos incentiva a aceitação e demanda dos consumidores. A elaboração de queijos constitui uma das mais importantes atividades na indústria de laticínios, sobretudo, nas regiões sul e sudeste do Brasil, cuja produção se concentra principalmente em indústrias de pequeno e médio porte [7].

Isso se deve, em parte, ao maior rendimento obtido na elaboração desses queijos, ao processamento simples que requerem e à ausência de maturação do produto final, o que possibilita um retorno rápido do investimento e, conseqüentemente, custos menores aos consumidores [7-9].

O queijo de Coalho é um queijo típico das regiões Norte e Nordestes do país, destacando-se como o principal queijo artesanal incorporado à cultura de nossa região. Sua produção está concentrada nos estados de Pernambuco, Ceará, Rio Grande do Norte e Paraíba. É um produto muito consumido no nordeste, quer que seja assado, na brasa ou frito, o que também o torna um produto bastante usado na culinária. A maior parte da fabricação ainda é artesanal e feita com leite cru. Principalmente por uma parcela considerável de pequenos produtores estabelecidos na zona rural.

Devido às características deste produto, ou seja, seu sabor peculiar e principalmente as diferentes maneiras de consumo este queijo vem a cada dia ganhando novos consumidores de vario estado do país. Essa nova oportunidade de mercado vem despertando grande interesse de varias empresas do setor, em incorpora a tecnologia do “queijo de coalho" em sua linha de produção. Atualmente, em função do grande consumo, já existe uma legislação nacional especifica, através do Regulamento técnico de Identidade e Qualidade de Produtos Lácteos, o qual estabelece os padrões de identidade e os requisitos mínimos de qualidade que o queijo coalho deverá cumprir para ser destinado ao consumo humano. Os queijos e outros produtos lácteos são importantes na alimentação porque apresentam teor relevante de lipídios, proteínas, minerais e vitaminas, sendo, portanto um alimento completo [10]. A atuação das lipases intensifica características sensoriais e modifica as propriedades físico-químicas do queijo [11]. Logo, o objetivo deste trabalho foi analisar os parâmetros físico - químicos do queijo Coalho comercializado nno município de Barreiros - PE. 


\section{Materiais e Métodos}

\subsection{Materiais}

Amostras de queijo coalho sem denominação de origem e sem certificação do Serviço de Inspeção Federal (SIF) foram adquiridas ao acaso, no período de 20 de julho a 20 de dezembro de 2007 em pequenos mercadinhos na cidade dos Barreiros - PE. As amostras diferentes foram analisadas em triplicata quanto aos parâmetros físico-químicos de qualidade: teores de umidade, determinação de amido, extrato seco, teor de cloretos, acidez titulável e cinzas. No experimento foi utilizado balança analítica, centrífuga, estufa, mufla e potenciômetro.

Após a retirada das porções das amostras, essas foram devidamente homogeneizadas em um “blender”, seguindo-se armazenamento em sacos plásticos estéreis de polietileno, sendo colocadas em geladeira (máximo $10^{\circ} \mathrm{C}$ ) para que as análises fossem processadas durante a semana, tomandose a precaução de realizar- se sempre as de acidez e pH imediatamente.

\subsection{Métodos de análise}

Para as análises físico-químicas as amostras foram preparadas de acordo com os métodos analíticos oficiais, publicados pelo LANARA [12].

$\mathrm{O}$ teor de umidade foi quantificado pela secagem das amostras em estufa a $95^{\circ} \mathrm{C}$ até peso constante.

O extrato seco total (EST) foi obtido pela diferença da umidade em 100 gramas da amostra [13].

Determinou-se o teor de cloreto diretamente na amostra, segundo método modificado por FURTADO [13].

Cinzas - determinada em mufla a $550{ }^{\circ} \mathrm{C}$, pelo método gravimétrico;

A acidez foi determinada utilizando o método Dornic.

\section{Resultados e Discussão}

Os resultados das análises físico-químicas e os valores médios de umidade, extrato secos, cloreto e cinzas, para os respectivos tempos e tratamentos do queijo Coalho comercializados na cidade de Barreiros/PE, são apresentados na Tabela 1. 
Tabela 1. Parâmetros físico-químicos do queijo Coalho comercializado em Barreiros.

\begin{tabular}{lcccc}
\hline \multicolumn{1}{c}{ Parâmetros } & Mínima & Máxima & Média $\pm \mathbf{S}^{*}$ & $\mathbf{C V}^{* *}$ \\
\hline \multirow{2}{*}{ Umidade (\%) } & 32,11 & 40,62 & $36,37 \pm 6,02$ & 16,55 \\
Acidez (\%) & 0,95 & 1,99 & $1,47 \pm 0,74$ & 50,34 \\
Cloretos (\%) & 1,85 & 2,15 & $2,00 \pm 0,21$ & 10,50 \\
Extrato Seco (\%) & 59,22 & 67,89 & $63,56 \pm 6,13$ & 9,64 \\
Cinzas (\%) & 3,85 & 4,77 & $4,31 \pm 0,65$ & 15,08 \\
\hline & $* *$ coeficiente de variação = (desvio padrão / média) x 100 &
\end{tabular}

Os resultados obtidos estão dentro de uma faixa de variação normal, a partir do momento que os coeficientes de variação dos diferentes parâmetros físico-químicos observados estão na maioria com valores de até 20\%, o que é considerado normal, segundo SAMPAIO [14], para respostas obtidas na área biológica.

Os altos valores de CV $(50,34)$ obtidos com relação à acidez podem ser explicados principalmente pela falta de padronização no processo de fabricação dos queijos.

Os valores de umidade encontraram-se entre 32,11 e 40,62g/100g, com média de 36,37g/100g, e apresentaram um coeficiente de variação de 16,55. Na análise do teor de umidade, os produtos apresentaram valores que diferiram estatisticamente ao nível de 5\% de significância. Segundo OLIVEIRA [15] o teor de umidade varia muito e está correlacionado com o tempo de conservação do queijo. Os mais desidratados são mais duros e apresentam maior conservação, mesmo em condições adversas.

Em relação ao teor de umidade, que variou de 32,11\% a 40,70\%, nenhuma amostra continha um excedente, ou seja, ultrapassaram 55\% de água. A umidade interfere na atividade de água (Wa) e nas ações metabólicas de microorganismos ao longo da maturação, com suas possíveis conseqüências no pH, na textura, no sabor e no aroma.

Com relação a análises de extrato seco (ES) pode-se observar que as amostras apresentaram resultados diferentes. Os resultados para o ES apresentaram comportamento inversamente proporcional ao da umidade. Tais resultados apresentaram-se semelhantes aos encontrados por BONASSI \& GOLDONI [16], SAITO \& SCHIFTAN [17] e SCHIFTAN \& KOMATSU [18] em estudo sobre a composição centesimal dos queijos tipo "minas", "minas frescal" e "prato", respectivamente.

Encontrou-se uma média de 63,56g/100g de estrato seco nas amostras estudadas, sendo 59,22/100g e 67,89/ 100g os valores máximo e mínimo encontrados. 
Neste estudo, ao analisar o teor de cinzas observou-se que o menor valor de no teor foi 3,85g/100g. Os valores de cinzas encontraram-se entre 3,85 e 4,77/100g, com média de 4,31/100g, e apresentaram um coeficiente de variação alto $(15,08)$.

O valor encontrado para cloreto apresentou média de 2,00g/100g nas amostras estudadas, sendo 2,15g/100g e 1,85g/ 100g os valores máximo e mínimo encontrados.

Além de modificar o sabor do produto, o sal regula a atividade enzimática em diversos níveis, afetando o crescimento bacteriano e o desenvolvimento da proteólise. Isto tornou-se evidente na comparação do teor de cloretos do queijo.

\title{
4. Conclusões
}

Os valores médios encontrados para os parâmetros físico-químicos foram: umidade36,37g/100g; cinzas-4,31g/100g; cloretos-2,00g/100g; acidez- 1,47(g/100g de ácido láctico); extrato seco - 63,56g/100g. Não houve diferença $(p>0,05)$ entre os queijos comercializados em Barreiros/PE para os parâmetros físico-químicos.

O teor de umidade dos queijos estudados variou de 32,11\% a 40,70\%. As alterações das características físico-químicas ocorreram em todas as amostras. Os dados obtidos neste trabalho mostraram que queijo com alterações físico-químicas ocorreram principalmente em relação ao teor de umidade e teor de cloreto.

Com relação ao teor de cloreto presente nos queijos estudados percebe-se nos três ensaios realizados percebe-se uma variação entre 1,85-2,05. O amido utilizado para proporcionar consistência ao queijo, não foi encontrado em nenhuma das amostras.

\begin{abstract}
The objective of this research was to evaluate the physicochemical quality of marketable coalho type cheese marketed in the city of the Barreiros- PE. Samples were collected in five (5) small supermarkets of Barreiros - PE from July to December. The physical-chemical parameters average values found were: moisture content- $36.37 \mathrm{~g} / 100 \mathrm{~g}$; ashes-4.31g/100g; chlorides- $2.00 \mathrm{~g} / 100 \mathrm{~g}$; titrable acidity- $1.47 \mathrm{~g} / 100 \mathrm{~g}$ of lactic acid); dry extract $-63.56 \mathrm{~g} / 100 \mathrm{~g}$. There was no significant difference $(p>0,05)$ between the cheeses marketable in Barreiros - PE for the physical-chemical parameters.
\end{abstract}

Key-words: coalho type cheese; physical-chemical quality; moisture content.

\section{Referências}

[1] FLORENTINO ER, MARTINS RS. Características microbiológicas do “queijo de coalho” produzido no Estado da Paraíba. Revista Higiene Alimentar, v.13, n. 59, p. 43-48, 1999.

[2] AQUINO FT. Produção de queijo de coalho na Paraíba: acompanhamento das características físico-químicas do processamento. Dissertação de mestrado- centro de tecnologia. Universidade Federal da Paraíba, João Pessoa, 1983. 88p. 
[3] SENA, M.J.; CERQUEIRA, M.M.O.P.; MORAIS, C.F.A.; CORRÊA, E.S.; SOUZA, M.R. Características físicoquímicas de queijo de coalho comercializado em Recife-PE. Revista Higiene Alimentar, v.14, n.74, p.41-44, 2000.

[4] ALMEIDA FILHO, E. S. Características microbiológicas do queijo tipo minas frescal produzido artesanalmente e comercializado no Município de Poços de Caldas-MG. 1999. 60p. Dissertação (Mestrado) - Faculdade de Ciências Agrárias e Veterinárias Campus de Jaboticabal, Unesp, Jaboticabal, 1999.

[5] ANUALPEC. Mudança de escala na pecuária de leite. Anuário da Pecuária Brasileira. p.223-230, 1998.

[6] ORMENESE, R. de C. S. C. ; SILVEIRA, N. F. A. ; SILVA, N. da. Escherichia coli 0157:H7 em alimentos. In: Bol. SBCTA, 33(1):41-49, jan/jun 1999.

[7] PINTO, P.S.A.; GERMANO, M.I.S.; GERMANO, P.M.L. Queijos minas: problemas emergentes de vigilância sanitária. Higiene Alimentar, v.10, n.44, p.22-27, 1996.

[8] BEHMER, M.L.A. Tecnologia do leite. São Paulo: Editora Nobel, 1984. 250p.

[9] FELÍCIO FILHO, A. Eficiência econômica de estocagem de queijos. Informe Agropecuário, v.10, n. 21, p.6-11, 1984.

[10] ABIQ - Associação Brasileira das Indústrias de Queijo. Benefícios nutricionais dos queijos. ABIQ, 2005.

[11] FURTADO \& CHANDAN, 1983 Queijo Gorgonzola fabricado com Leite Pasteurizado por ejetor de vapor e HTST: Parâmetros Físico-Químicos e sensoriais. Brasília, Janeiro 2000.

[12] LANARA. LABORATÓRIO NACIONAL DE REFERÊNCIA ANIMAL. Métodos analíticos oficiais para controle de produtos de origem animal e seus ingredientes. II: Métodos físicoquímicos. Brasília, 1981 b.

[13] FURTADO, J. P. Análises bromatológicas. Juiz de Fora: UFJF, 1975. 97 p.

[14] SAMPAIO, I.B. M. Estatística aplicada à experimentação animal. Belo Horizonte: Fundação de Ensino e Pesquisa em Medicina Veterinária e Zootecnia, 1998.

[15] OLIVEIRA, J. S. de. Queijo: fundamentos tecnológicos. São Paulo: Secretaria da Indústria, Comércio, Ciência e Tecnologia / Fundação Tropical de Pesquisas e Tecnologia, 1981. 233 p.

[16] BONASSI, J.A. \& GOLDONI, J.S. Influênciadas bactérias láticas mesófilas: Streptococcus cremoris, Streptococcus lactis, Streptococcus diacetilactis e Leuconostoc citrovorum. Composição centesimal. in: Anais do IV Congresso Brasileiro de Ciência e Tecnologia de Alimentos. Rio de Janeiro, p. 285-293.1980.

[17] SAITO, T. \& SCHIFTAN, T. Estudos da composição de queijos minas frescal, fabricado no Estado de São Pualo. Rev. Insto Latic. Cândido Tostes. Juiz de Fora. 33 (199): 29-37,1978.

[18] SCHIFTAN, T. \& KOMATSU, L. Estudo sobre a composição do queijo prato consumido na cidade de São Paulo. Rev. Insto Latic. Cândido Tostes, Juiz de Fora. 35 (207); 33-8, 1980.

\section{Dados do primeiro autor:}

Nome completo: João Rufino de Freitas Filho

Filiação institucional: Universidade Federal Rural de Pernambuco

Departamento: Unidade Acadêmica de Garanhuns

Função ou cargo ocupado: Professor Adjunto I

Endereço completo para correspondência (bairro, cidade, estado, país e CEP): Av. Lions Club, Aluísio Pinto, Garanhuns, Pernambuco, Brasil, CEP: 55292-060

Telefones para contato: (87)3762-0438 Celular (87)99995855

e-mail: joaoveronice@yahoo.com.br 